\title{
Understanding factors affecting patient and public engagement and recruitment to digital health interventions: a systematic review of qualitative studies
}

Siobhan O'Connor ${ }^{1,2}$, Peter Hanlon ${ }^{1}$, Catherine A. O'Donnell', Sonia Garcia ${ }^{3}$, Julie Glanville ${ }^{3}$ and Frances S. Mair ${ }^{1 *}$

\begin{abstract}
Background: Numerous types of digital health interventions (DHIs) are available to patients and the public but many factors affect their ability to engage and enrol in them. This systematic review aims to identify and synthesise the qualitative literature on barriers and facilitators to engagement and recruitment to DHIs to inform future implementation efforts.
\end{abstract}

Methods: PubMed, MEDLINE, CINAHL, Embase, Scopus and the ACM Digital Library were searched for English language qualitative studies from 2000 - 2015 that discussed factors affecting engagement and enrolment in a range of DHIs (e.g. 'telemedicine', 'mobile applications', 'personal health record', 'social networking'). Text mining and additional search strategies were used to identify 1,448 records. Two reviewers independently carried out paper screening, quality assessment, data extraction and analysis. Data was analysed using framework synthesis, informed by Normalization Process Theory, and Burden of Treatment Theory helped conceptualise the interpretation of results.

Results: Nineteen publications were included in the review. Four overarching themes that affect patient and public engagement and enrolment in DHls emerged; 1) personal agency and motivation; 2) personal life and values; 3) the engagement and recruitment approach; and 4) the quality of the DHI. The review also summarises engagement and recruitment strategies used. A preliminary Dlgital Health EnGagement MOdel (DIEGO) was developed to highlight the key processes involved. Existing knowledge gaps are identified and a number of recommendations made for future research. Study limitations include English language publications and exclusion of grey literature.

Conclusion: This review summarises and highlights the complexity of digital health engagement and recruitment processes and outlines issues that need to be addressed before patients and the public commit to digital health and it can be implemented effectively. More work is needed to create successful engagement strategies and better quality digital solutions that are personalised where possible and to gain clinical accreditation and endorsement when appropriate. More investment is also needed to improve computer literacy and ensure technologies are accessible and affordable for those who wish to sign up to them.

Systematic review registration: International Prospective Register of Systematic Reviews CRD42015029846

Keywords: Digital health, eHealth, Electronic health records, Telemedicine, Mobile applications, mHealth, Engagement, Recruitment, Barrier, Facilitator

\footnotetext{
* Correspondence: Frances.Mair@glasgow.ac.uk; Francses.Mair@glasgow.ac.uk

${ }^{1}$ General Practice and Primary Care, Institute of Health and Wellbeing,

University of Glasgow, 1 Horslethill Rd, Glasgow G12 9LX, UK

Full list of author information is available at the end of the article
} 


\section{Background}

Patients are beginning to use a range of digital health interventions (DHIs) to manage chronic illness at home and support independent living and self-care, while remaining connected to health and care providers [1]. DHIs may address many of the problems patients experience with today's health systems, such as poor access, uncoordinated care and increasingly costly healthcare [2]. Furthermore, DHIs aimed at the public are seen as one way to promote preventative health, potentially reducing health service utilisation and cost long-term [3]. DHIs range from telehealth and telecare systems [4], to patient portals and personal health records (PHRs) [5, 6], mobile health applications [7], and other online platforms and devices [8]. As the technology diversifies, miniaturises and becomes more interconnected, the shift towards using such DHIs will continue to grow.

However, numerous barriers prevent people from participating in evaluations of DHIs such as being too busy, feeling incapable of using the technology or disliking its' impersonal nature $[9,10]$. There are also factors that help patients and the public to engage with these electronic platforms such as personal motivation to improve health and learn new ways to manage illness [11]. Much of this evidence has been generated through quantitative methods, in particular Randomized Controlled Trials (RCTs), which provide little detail or context of the realworld difficulties individuals' face [12, 13] such as the cost of the technology and issues around privacy and security [14]. Understanding these problems is particularly important as we move from recruiting to RCTs, to engaging and enrolling patients and the public in largescale deployments of digital health in real world settings. This gap in knowledge is often referred to as the second translation gap, moving from initial concept testing and RCTs to full-scale implementation $[15,16]$.

Although an increasing number of qualitative studies have examined some of these issues, quite often they have focused on a particular patient population and a single piece of technology $[17,18]$. Therefore, the literature is fragmented and does not present a clear picture of the barriers and facilitators people face when engaging and enrolling in all types of DHIs. Qualitative syntheses can aid our understanding of how complex interventions are embedded into daily routine, which can help to inform health policy and clinical practice $[19,20]$. A qualitative review of public engagement with eHealth has been conducted [21] but the majority of included studies looked at people who searched for health information online only, so it is limited in terms of its technological scope and it was undertaken in 2009, six years ago, which is a long time in a fast moving area. The review also lacked any assessment of the quality of included studies and had no theoretical basis, thereby diminishing the lessons that can be drawn from it.
This paper aims to address the fragmentation of research evidence by systematically reviewing and synthesising the qualitative literature on barriers and facilitators patients' and the public experience during engagement and recruitment to DHIs. It will also outline the strategies described to get people engaged and signed up to DHIs in the published literature. To address the lack of theoretical insights in this area, two empirically grounded theories will be utilised to aid in the conceptualisation of the complexities involved and develop a model of these processes. A series of recommendations about how patients and the public can be better supported to take up digital health products and services will also be outlined to improve the initial phases of the digital health implementation journey. Any outstanding research gaps will also be highlighted.

\section{Methods}

A protocol was created and the review registered on PROSPERO, the International Register of Systematic Reviews (CRD42015029846, http://www.crd.york.ac.uk/ PROSPERO/display_record.asp?ID=CRD42015029846).

\section{Search strategy}

A scoping search was conducted to identify key papers and search terms to inform the design of the search protocol. This included three groups of concepts: (1) engagement and recruitment, (2) DHIs, and (3) barriers and facilitators. As it was thought important to capture the views of multiple stakeholders who would be aware of the experiences of patients and the public the population was not specified. A combination of MeSH headings, free text search terms and a novel text mining approach were used to narrow the considerable digital health literature and overcome the challenges of identifying relevant papers, which is described in detail elsewhere [22]. Six online bibliographic databases; CINAHL (EBSCHOHost), PubMed, Medline, Embase, Scopus and the ACM Digital Library, were searched for English language publications between January 1, 2000 and August 19, 2015 (see Additional file 1). Reference and citation tracking, the 'Similar articles' function in PubMed, personal knowledge, and contacting experts in the field were also utilised to identify relevant papers. Endnote was used to remove duplicate citations before screening.

\section{Selection criteria}

Qualitative studies that explored the reasons why patients' or the public engaged and enrolled in a range of digital health interventions were included (see Table 1).

\section{Screening, data extraction and quality appraisal}

The titles, abstracts and full papers were screened independently by two reviewers using DistillerSR software. Any discrepancies were discussed and disagreements 
Table 1 Inclusion and exclusion criteria used for the screening process

\begin{tabular}{|c|c|}
\hline \multicolumn{2}{|l|}{ Inclusion criteria } \\
\hline \multirow[t]{4}{*}{ Study type } & Publication date from 2000 present. \\
\hline & Studies from any geographical location. \\
\hline & English language. \\
\hline & $\begin{array}{l}\text { Original qualitative studies, studies involving secondary analysis of qualitative data or } \\
\text { qualitative studies that are part of a mixed methods study (e.g. the study also has a } \\
\text { quantitative component but the major component is qualitative and a qualitative } \\
\text { methodology is described). The study must have direct contact with individuals or } \\
\text { direct observation using any form of qualitative method. }\end{array}$ \\
\hline Participant Type & $\begin{array}{l}\text { Any individual (adult or child). This includes patients, the public and health professionals } \\
\text { who would be aware of the experiences of these groups. }\end{array}$ \\
\hline Type of digital health intervention & $\begin{array}{l}\text { Any health intervention delivered by a digital technology (hypothetical or in development, } \\
\text { simulated or real-world) which takes information from patients or the public or provides } \\
\text { some form of advice or feedback about their health. This includes, but is not limited to: } \\
\text { - Web-based interventions on personal computers (PCs) or mobile platforms, } \\
\text { - Mobile health applications or apps, } \\
\text { - Patient portals or personal health records, } \\
\text { - Interventions delivered by short message service (SMS) or interactive voice recognition (IVR). }\end{array}$ \\
\hline Setting & $\begin{array}{l}\text { Any 'usual' setting (hypothetical or in development, simulated or real-world) such as primary, } \\
\text { secondary or tertiary care, the home or workplace. }\end{array}$ \\
\hline Phase of implementation & $\begin{array}{l}\text { Engagement and recruitment phase of a digital health intervention, which can span from } \\
\text { gauging an individual's readiness for a digital health intervention, to the initial marketing or } \\
\text { reach of the initiative, to actively signing individuals up to use the technology so they are } \\
\text { registered on the digital application or system. }\end{array}$ \\
\hline \multicolumn{2}{|l|}{ Exclusion criteria } \\
\hline \multirow[t]{9}{*}{ Study Type } & Published pre 2000. \\
\hline & Non English language. \\
\hline & Grey literature/not published in a peer reviewed journal. \\
\hline & Dissertation/thesis. \\
\hline & Published abstracts or conference proceedings. \\
\hline & $\begin{array}{l}\text { Studies using the following methodologies: descriptive case studies, lexical studies that analyse } \\
\text { natural language data presented as qualitative results; qualitative studies using questionnaires } \\
\text { or other methods that do not involve direct contact or observation of participants. }\end{array}$ \\
\hline & $\begin{array}{l}\text { Any type of literature review, systematic review and meta-analyses, or a qualitative study that } \\
\text { did not involve direct contact or observation of participants. }\end{array}$ \\
\hline & $\begin{array}{l}\text { Randomized Controlled Trials due to the large volume of literature on the difficulties recruiting } \\
\text { to clinical trials that already exists [94]. }\end{array}$ \\
\hline & $\begin{array}{l}\text { Commentary articles, written to convey opinion or stimulate research/discussion, with no } \\
\text { research component. }\end{array}$ \\
\hline Type of digital health intervention & $\begin{array}{l}\text { Primary digital intervention is; telephone based with no additional technological function } \\
\text { (e.g. telephone counselling or triaging service); Internet based with no additional interactive } \\
\text { function (e.g. searching for health information online); or an implantable device that is remotely } \\
\text { monitored }\end{array}$ \\
\hline Setting & Any non-usual setting e.g. prison, armed forces in active duty. \\
\hline \multirow[t]{2}{*}{ Stage of implementation } & $\begin{array}{l}\text { Pre-implementation work based solely around designing the interface and functionality of the } \\
\text { digital health intervention. }\end{array}$ \\
\hline & $\begin{array}{l}\text { The post engagement/recruitment phase will not be explored. For example: } \\
\text { - why patients or the public use or do not use digital health interventions, } \\
\text { - why they drop out (attrition) or fail to continue using them (retention), } \\
\text { - their attitudes or beliefs towards digital health interventions, or their satisfaction with them } \\
\text { outside of that pertaining directly to engagement and recruitment. }\end{array}$ \\
\hline
\end{tabular}

adjudicated by a third party. A standardised data extraction template was then used which addressed a number of study characteristics (see Additional file 2). Text pertaining to barriers, facilitators, engagement and recruitment strategies, which included findings and interpretations written by the authors or participant quotes, were regarded as data and extracted for coding. Two reviewers independently performed a quality assessment using the 
32-item Consolidated Criteria for Reporting Qualitative Research (COREQ) checklist [23, 24]. Although some would argue against such critical appraisal due to the unique philosophical and methodological underpinnings of qualitative work and the sometimes prescriptive use of such checklists [25, 26], others believe applying quality standards enables a more thorough exploration of the contribution of each study thereby improving the credibility of qualitative synthesis [27]. All articles meeting the inclusion criteria were retained, regardless of their quality, as even methodologically weak studies can sometimes offer valuable insights $[28,29]$.

\section{Data analysis}

Our qualitative synthesis was informed by the framework approach $[30,31]$ as it provides a robust process to support analysis [32]. An empirically grounded theory, Normalization Process Theory (NPT) [33, 34], was used to underpin the process. NPT is a useful heuristic device to explain how people individually and collectively embed new interventions in everyday routine through four generative mechanisms: sense-making work; relational work; operational work; and appraisal work (see Table 2) and it has been used successfully in other systematic reviews $[35,36]$. This provided a solid theoretical basis to develop a new conceptual model of digital health engagement and recruitment processes. Each item of extracted data was coded independently by two researchers. Coding clinics were held with a third researcher to ensure consistency of approach. Codes were compared and contrasted in a framework, then categorised and classified into higher order themes that were mapped onto the generative mechanisms of NPT. NVivo
QSR 10.0 was used to facilitate analysis. During this process common themes began to emerge, indicating data saturation. Any negative data was carefully noted to ensure the new conceptual model was appropriate and any variances accounted for [37]. Burden of Treatment Theory (BOTT) was then used as a lens to develop recommendations for successfully enabling patients and the public to engage with digital health, as it describes how people cope with new interventions and enact self-care practices through their relationships with formal and informal health and care networks $[38,39]$.

\section{Results}

In total, 1,448 records were identified, of which 290 full text articles were screened and 19 were selected for inclusion in the review (see Fig. 1). The reporting of this review follows the Enhancing Transparency in Reporting the Synthesis of Qualitative Research (ENTREQ) statement [40].

\section{Characteristics of included studies}

A summary of the characteristics of included studies and participants can be found in Additional file 3. The included studies were published between 2005 and 2015, with the majority being published in the last four years. The studies were published in a number of countries with eight taking place in the United Kingdom [41-48], five in the United States [49-53], four in Canada [54-57] and one each in Norway [58] and Spain [59]. They spanned numerous types of DHIs including patient accessible electronic health records and PHRs [47, 48, 57], a telehealth system for diabetics [49], web-based sexual health and cognitive behavioural therapy services $[42-45,55,56]$, an

Table 2 NPT Coding Framework

\begin{tabular}{|c|c|c|c|}
\hline Coherence (CO) & Cognitive Participation (CP) & Collective Action (CA) & Reflexive Monitoring (RM) \\
\hline $\begin{array}{l}\text { The sense-making work that people } \\
\text { do individually and collectively when } \\
\text { faced with engaging and enrolling } \\
\text { in a digital health intervention }\end{array}$ & $\begin{array}{l}\text { The relational work that people } \\
\text { do individually and collectively to } \\
\text { build and sustain engagement } \\
\text { and enrolment in a digital health } \\
\text { intervention }\end{array}$ & $\begin{array}{l}\text { The operational work that } \\
\text { people do by investing effort and } \\
\text { resources to engage with and sign } \\
\text { up to a digital health intervention }\end{array}$ & $\begin{array}{l}\text { The appraisal work that people } \\
\text { do to evaluate engagement and } \\
\text { recruitment to a digital health } \\
\text { intervention that affects them } \\
\text { and others around them }\end{array}$ \\
\hline Differentiation (CO-d) & Enrolment (CP-e) & Skillset Workability (CA-sw) & Reconfiguration (RM-r) \\
\hline $\begin{array}{l}\text { Defining, dividing up and } \\
\text { categorizing tasks }\end{array}$ & $\begin{array}{l}\text { Recruiting the self and others } \\
\text { to tasks }\end{array}$ & Allocating tasks and performances & Modifying or changing tasks \\
\hline Communal Specification (O-cs) & Activation (CP-a) & Contextual Integration (CA-ci) & Communal Appraisal (RM-ca) \\
\hline $\begin{array}{l}\text { Making sense of shared versions } \\
\text { of tasks }\end{array}$ & $\begin{array}{l}\text { Organising a shared } \\
\text { contribution to tasks }\end{array}$ & $\begin{array}{l}\text { Supporting, resources and integrating } \\
\text { tasks in their social contexts }\end{array}$ & $\begin{array}{l}\text { Shared evaluation of } \\
\text { contributions to tasks }\end{array}$ \\
\hline Individual Specification (CO-is) & Initiation (CP-i) & Interactional Workability (CA-iw) & Individual Appraisal (RM-ia) \\
\hline $\begin{array}{l}\text { Making sense of personal versions } \\
\text { of tasks }\end{array}$ & $\begin{array}{l}\text { Organizing an individual } \\
\text { contribution to tasks }\end{array}$ & $\begin{array}{l}\text { Doing tasks, and achieving outcomes } \\
\text { in practice }\end{array}$ & $\begin{array}{l}\text { Individual evaluation of } \\
\text { contributions to tasks }\end{array}$ \\
\hline Internalization (CO-i) & Legitimation (CP-I) & Relational Integration (CA-ri) & Systematization (RM-s) \\
\hline Learning how to do tasks in context & $\begin{array}{l}\text { Making tasks the right thing } \\
\text { to do }\end{array}$ & $\begin{array}{l}\text { Developing confidence and } \\
\text { communicating reliable knowledge } \\
\text { about tasks }\end{array}$ & $\begin{array}{l}\text { Organizing a reliable stock of } \\
\text { knowledge about tasks }\end{array}$ \\
\hline
\end{tabular}




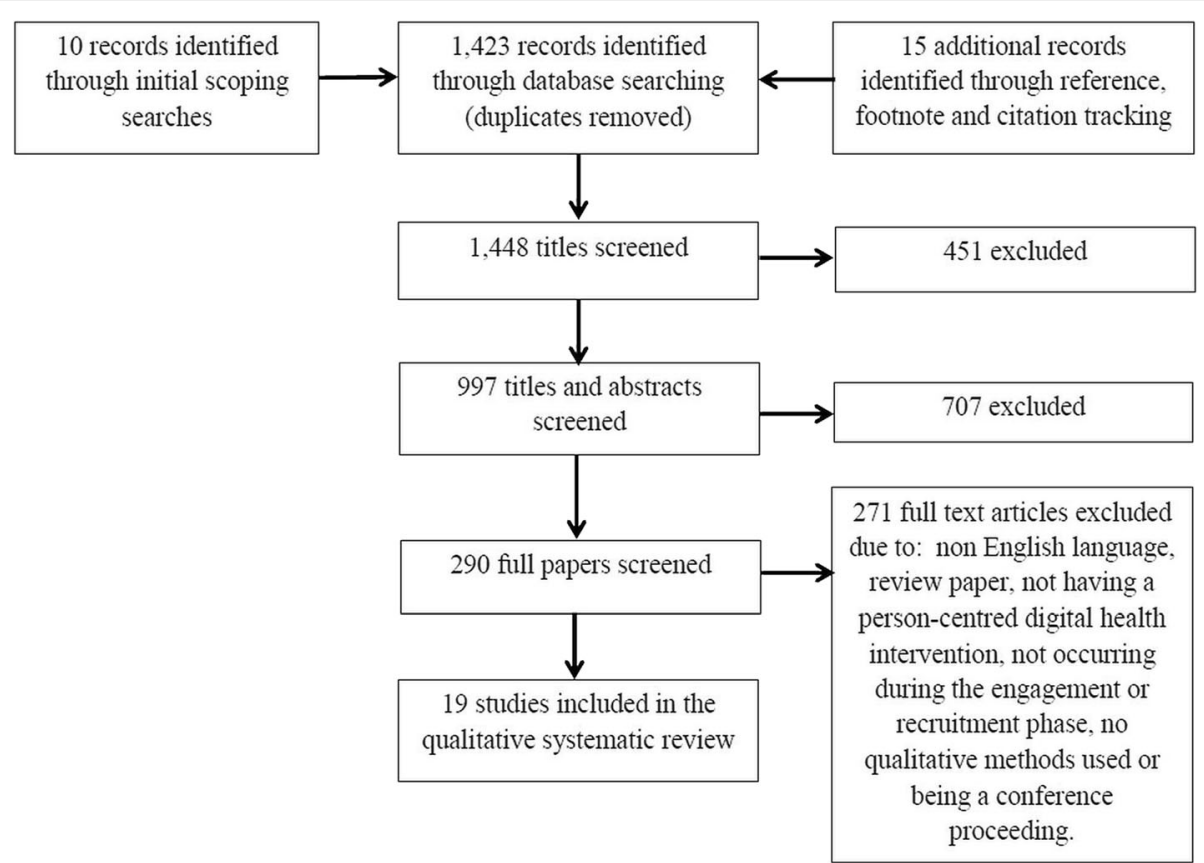

Fig. 1 Preferred Reporting Items for Systematic Reviews and Meta-Analysis (PRISMA) flow diagram of search strategy to identify articles

online appointment booking and patient provider communication system [46, 58], an Internet support group [53]; a social networking application [50]; and email, SMS or mobile phone based health promotion, smoking cessation or weight loss programmes [41, 51, 52, 59]. Only one study was a mixed intervention combining a pedometer with nutritional education and meal preparation training [54]. Fifteen studies were purely qualitative using a combination of interviews, focus groups, participant observation and documentary evidence [41-45, 47, 49, 52-59] with only four studies adopting mixed method approaches $[46,48,50,51]$. The participants in the studies were patients, carers and healthy individuals from a variety of ages, genders, socioeconomic groups and ethnicities [42, 44, 45, 47, 48, 50-59] or were health professionals such as nurses or family doctors [43, 44, 46, 48, 49, 59]. Three studies had a mixture of other participants such as employees of large public and private companies, general practice staff and a range of individuals from local and national organisations affiliated with the implementation of a DHI [41, 46, 48]. However, several studies did not describe participant characteristics in detail: with three not depicting gender [44, 48, 49], four not portraying age $[43,44,48,49]$, nine not describing socio-economic status [43-46, 48, 49, 56, 57, 59], and eleven not highlighting ethnicity in detail [41, 43-46, 48, $49,55,57-59]$. In general there was a trend towards younger and more middle aged people, rather than older adults, and those of "white" ethnicity.

\section{Engagement and recruitment strategies}

A range of engagement and recruitment strategies for DHIs were described. We classified engagement as any process by which patients' and the public became aware of or understood a DHI for example through promotional efforts and marketing campaigns. These ranged from multiple forms of advertising to the use of health professionals, family and friends. DHIs were advertised on radio $[47,48]$, in print media such as newspapers; personal letters; posters on notice boards; printed flyers and leaflets [41, 46-49, 51], via electronic media e.g. television screens and digital notice boards and online via email, social media, website and Internet communities or forums [41, 46, 48]. More traditional forms of direct engagement were also employed such as consultations with health professionals [45, 47-49], employers [41], personal recommendations from family or friends [54] or being spoken to by research or management staff $[46,58]$. Co-design activities were also utilised to get patients and the public involved in creating a DHI $[42,52,55,59]$. We distinguished enrolment as any approach that involved people actively registering for or signing up to a DHI. Enrolment strategies were similarly wide ranging, with different levels of participation required from individuals. They included filling out paper based registration forms [45, 48, 58], sending a SMS text message [51], creating an online account or profile [41, 48, 51] or getting personal assistance from a health professional, administrator or researcher to do so $[48,49,51]$, 
or in one particular instance consent was implied and an online account was automatically created [47]. In general, the engagement and enrolment strategies used in the included studies were not described in detail but are summarised in Table 3. There was insufficient data in the included studies to allow us to build a full taxonomy of engagement and enrolment strategies.

\section{Quality appraisal}

The quality of reporting in the included studies varied with between 10 and 24 of the 32 items from the COREQ checklist (see Additional file 4) [23]. All 19 studies included the sample size, presented the main themes clearly and demonstrated consistency between the data collected and the findings. Seventeen provided some type of interview guide and described how participants were approached. Only one study reported repeating interviews and one returning transcripts to respondents. Overall the studies were of reasonable quality.

\section{Issues affecting digital health engagement and recruitment}

Four major themes and several subthemes related to barriers and facilitators to engagement and recruitment in DHIs emerged (see Table 4). The four main themes

Table 3 List of digital health engagement and recruitment strategies

\begin{tabular}{|c|c|}
\hline \multicolumn{2}{|l|}{ Engagement Strategy } \\
\hline Advertising (Indirect) & $\begin{array}{l}\text { Electronic media - television screens } \\
\text { and digital notice boards } \\
\text { Online media - email; social media; } \\
\text { websites; Internet communities or } \\
\text { forums } \\
\text { Print media - newspaper advertising; } \\
\text { personal letters; posters on notice } \\
\text { boards; printed flyers and leaflets } \\
\text { Radio }\end{array}$ \\
\hline Personal Contact (Direct) & $\begin{array}{l}\text { During a consultation with a health } \\
\text { professional } \\
\text { Research or management staff within a } \\
\text { healthcare facility } \\
\text { During a consultation with an employer } \\
\text { Family, friends or peers } \\
\text { Co-design activities }\end{array}$ \\
\hline \multicolumn{2}{|l|}{ Recruitment Strategy } \\
\hline Automatic & $\begin{array}{l}\text { Consent is assumed and a digital } \\
\text { profile or account is created }\end{array}$ \\
\hline Electronic & Register online via a website \\
\hline Paper based & $\begin{array}{l}\text { Complete a paper based registration } \\
\text { form }\end{array}$ \\
\hline Personal Assistance & $\begin{array}{l}\text { Healthcare professional helps to create } \\
\text { a digital profile or account }\end{array}$ \\
\hline Telephone or mobile phone & $\begin{array}{l}\text { Telephone registration line } \\
\text { Send a SMS text message }\end{array}$ \\
\hline
\end{tabular}

are: 1) personal agency and motivation; 2) personal life and values; 3) engagement and recruitment approach; and 4) the quality of the DHI. Participant quotes are provided in the text to substantiate the data in each theme and more are available in Additional file 5.

\section{Personal agency and motivation}

The first theme that emerged concerned personal agency and motivation, as patients and members of the public who wanted to be healthy or have more choice and control over managing their wellbeing tended to engage and enrol in DHIs. They saw technology as a good way to maintain motivation to be physically active and lose weight, while preventing the onset of disease $[41,49,54,59]$. Many people signed up to a DHI as it gave them the choice to access health information when and where it suited, which in some cases helped reduce anxiety $[41,43,55,56,59]$. People also liked the level of control technology offered in terms of monitoring and understanding health related behaviours, such as diet and exercise, or self-managing chronic conditions and this encouraged registration $[48,49,57]$.

\section{"[I subscribed] to get the reminders, because if you're sat, if you are in a lunch break and you're sat at your desk just on the Internet and you're not moving and you're eating something that's not good and then you get a reminder and it's just: 'have a walk!', or something. Straight away there is a trigger in your mind and you think: 'yeah, that's right, I can do that!" - Facilitator (CO-i) [41]}

In contrast, a barrier to engaging for some was poor awareness of technology or seeing no value in the DHI offered or lacking the motivation to understand and improve their health through electronic data; this was often seen to be the role of their healthcare provider [48, 49]. For others the DHI was considered as a constant reminder of their failure to meet healthy goals and was thought to be discouraging $[52,54]$. Technology was also viewed as potentially disruptive by some or purely for entertainment purposes by others and not for healthcare needs $[47,48,52]$. Many people already used other ways to manage their health or illness, such as recording data via paper based systems, gaining support through family, friends and health professionals, or maintaining physical activity levels. They preferred to continue using these alternative approaches than convert to electronic solutions $[41,46-48,53,55]$.

"For me, it does not change anything because I am always in a car. I walk very little so I will feel even guilty for not having walked. I will look down at the low numbers and I'll feel anxious." - Barrier (CO-is) [54] 
Table 4 Factors affecting digital health engagement and recruitment

\begin{tabular}{|c|c|c|c|}
\hline \multirow{2}{*}{\multicolumn{2}{|c|}{$\begin{array}{l}\text { Barriers } \\
\text { Themes 1: Personal Agency and Motivation }\end{array}$}} & \multicolumn{2}{|l|}{ Facilitators } \\
\hline & & & \\
\hline $\begin{array}{l}\text { Barrier } \\
\text { Subtheme 1.1: } \\
\text { Lack of Motivation }\end{array}$ & $\begin{array}{l}\text { Lack of motivation to understand } \\
\text { or improve health }\end{array}$ & $\begin{array}{l}\text { Facilitator } \\
\text { Subtheme 1.1: } \\
\text { Personal Motivation }\end{array}$ & $\begin{array}{l}\text { Motivation to understand and } \\
\text { improve health }\end{array}$ \\
\hline $\begin{array}{l}\text { Barrier } \\
\text { Subtheme 1.2: } \\
\text { Awareness and understanding }\end{array}$ & $\begin{array}{l}\text { Unaware of or lacks } \\
\text { understanding of how a DHI } \\
\text { could be helpful }\end{array}$ & $\begin{array}{l}\text { Facilitator } \\
\text { Subtheme 1.2: } \\
\text { Awareness and } \\
\text { understanding }\end{array}$ & $\begin{array}{l}\text { Ability to understand a } \mathrm{DHI} \text { and } \\
\text { personal health data }\end{array}$ \\
\hline $\begin{array}{l}\text { Barrier } \\
\text { Subtheme 1.3: } \\
\text { Personal Agency (choice and } \\
\text { control) }\end{array}$ & $\begin{array}{l}\text { Alternative ways of } \\
\text { documenting health } \\
\text { information and managing } \\
\text { illness }\end{array}$ & $\begin{array}{l}\text { Facilitator } \\
\text { Subtheme 1.3: } \\
\text { Personal Agency (choice and } \\
\text { control) }\end{array}$ & $\begin{array}{l}\text { Ability to choose time and location } \\
\text { of interaction with a DHI } \\
\text { Ability to control electronic personal } \\
\text { health data }\end{array}$ \\
\hline \multicolumn{4}{|l|}{ Themes 2: Personal Life and Values } \\
\hline $\begin{array}{l}\text { Barrier } \\
\text { Subtheme 2.1: } \\
\text { Personal lifestyle }\end{array}$ & $\begin{array}{l}\text { Busy lifestyle with competing } \\
\text { priorities }\end{array}$ & $\begin{array}{l}\text { Facilitator } \\
\text { Subtheme 2.1: } \\
\text { Personal lifestyle }\end{array}$ & DHI fits with personal lifestyle \\
\hline \multirow{3}{*}{$\begin{array}{l}\text { Barrier Subtheme 2.2: } \\
\text { Skills and equipment }\end{array}$} & Poor digital literacy & \multirow{3}{*}{$\begin{array}{l}\text { Facilitator } \\
\text { Subtheme 2.2: } \\
\text { Skills and equipment }\end{array}$} & Good digital literacy \\
\hline & $\begin{array}{l}\text { Lack of access to equipment } \\
\text { and the Internet }\end{array}$ & & \multirow{2}{*}{$\begin{array}{l}\text { Has or can afford computer equipment } \\
\text { or mobile device, network } \\
\text { connectivity and a data plan }\end{array}$} \\
\hline & Cost of a DHI & & \\
\hline $\begin{array}{l}\text { Barrier Subtheme 2.3: } \\
\text { Privacy and security }\end{array}$ & $\begin{array}{l}\text { Concern over the security and } \\
\text { privacy of DHI information or } \\
\text { interaction }\end{array}$ & $\begin{array}{l}\text { Facilitator } \\
\text { Subtheme 2.3: } \\
\text { Privacy and security }\end{array}$ & $\begin{array}{l}\text { Values the privacy and anonymity } \\
\text { of DHI information or interaction }\end{array}$ \\
\hline \multicolumn{4}{|c|}{ Theme 3: Engagement and Recruitment Approach } \\
\hline \multirow{2}{*}{$\begin{array}{l}\text { Barrier } \\
\text { Subtheme 3.1: } \\
\text { Recruitment strategy }\end{array}$} & \multirow[t]{2}{*}{$\begin{array}{l}\text { Difficulty understanding the } \\
\text { recruitment message }\end{array}$} & \multirow{2}{*}{$\begin{array}{l}\text { Facilitator } \\
\text { Subtheme 3.1: } \\
\text { Recruitment strategy }\end{array}$} & $\begin{array}{l}\text { Active promotion and engagement } \\
\text { strategies }\end{array}$ \\
\hline & & & Health professional acts as a gatekeeper \\
\hline $\begin{array}{l}\text { Barrier } \\
\text { Subtheme 3.2: } \\
\text { Direct support }\end{array}$ & $\begin{array}{l}\text { Lack of support from family } \\
\text { members, friends or peers }\end{array}$ & $\begin{array}{l}\text { Facilitator } \\
\text { Subtheme 3.2: } \\
\text { Direct support }\end{array}$ & $\begin{array}{l}\text { Support from family members, friends } \\
\text { or peers offline }\end{array}$ \\
\hline $\begin{array}{l}\text { Barrier } \\
\text { Subtheme 3.3: } \\
\text { Personal advice }\end{array}$ & $\begin{array}{l}\text { Lack of advice and } \\
\text { recommendations from } \\
\text { trusted sources }\end{array}$ & $\begin{array}{l}\text { Facilitator } \\
\text { Subtheme 3.3: } \\
\text { Personal advice }\end{array}$ & $\begin{array}{l}\text { Recommended by family members, } \\
\text { friends or peers }\end{array}$ \\
\hline $\begin{array}{l}\text { Barrier } \\
\text { Subtheme 3.4: } \\
\text { Clinical endorsement }\end{array}$ & $\begin{array}{l}\text { Lack of clinical endorsement } \\
\text { and support for a DHI }\end{array}$ & $\begin{array}{l}\text { Facilitator } \\
\text { Subtheme 3.4: } \\
\text { Clinical endorsement }\end{array}$ & $\begin{array}{l}\text { Clinical accreditation and support } \\
\text { for a DHI }\end{array}$ \\
\hline \multicolumn{4}{|c|}{ Theme 4: Quality of the Digital Health Intervention } \\
\hline \multirow{3}{*}{$\begin{array}{l}\text { Barrier Subtheme } 4.1 \text { and } 4.2 \text { : } \\
\text { Negative digital health experience } \\
\text { (quality of information or interaction) }\end{array}$} & $\begin{array}{l}\text { Impersonal DHI (poor quality } \\
\text { information or interaction) }\end{array}$ & \multirow{3}{*}{$\begin{array}{l}\text { Facilitator } \\
\text { Subtheme } 4.1 \text { and } 4.2 \text { : } \\
\text { Positive digital health } \\
\text { experience (quality of } \\
\text { information or interaction) }\end{array}$} & $\begin{array}{l}\text { Open, honest digital interaction with } \\
\text { healthcare provider }\end{array}$ \\
\hline & $\begin{array}{l}\text { Lack of trust in DHI information } \\
\text { or interaction }\end{array}$ & & $\begin{array}{l}\text { Previous negative experience of health } \\
\text { services without a DHI }\end{array}$ \\
\hline & $\begin{array}{l}\text { Digital health interaction could } \\
\text { be abusive }\end{array}$ & & Social support from peers online \\
\hline \multirow{2}{*}{$\begin{array}{l}\text { Barrier Subtheme 4.3: } \\
\text { Usability of the DHI }\end{array}$} & $\mathrm{DHI}$ is difficult to use & \multirow{2}{*}{$\begin{array}{l}\text { Facilitator } \\
\text { Subtheme 4.3: } \\
\text { Usability of the DHI }\end{array}$} & \multirow{2}{*}{$\begin{array}{l}\text { DHI is easy to enrol in and use } \\
\text { (automated and integrated) }\end{array}$} \\
\hline & Complex registration process & & \\
\hline
\end{tabular}

\section{Personal life and values}

The second theme to emerge was how a busy personal life, with lots of competing priorities, affected patients and the public's ability to engage with and enrol in DHIs. Those who thought the technology was relevant or could be tailored to their needs and it fitted easily into their personal life tended to sign up for it $[41,43,52,55-57,59]$. In addition, those who had or were already familiar with using technology [43, 49] and were digitally literate $[43,49,57]$ found it easier to enroll as they had the right 
knowledge and skills to do so. Some people signed up as they liked the anonymity that online health services provided, feeling secure and free from the embarrassment and discrimination that they sometimes experienced in the real-world [43, 45, 47, 53, 55-57].

"This is definitely a service I would use, not only for the convenience factor but I mean, no matter how old we are, it's still an embarrassing issue for a lot of people." - Facilitator (CA-iw) [55]

Alternatively, where people had demanding careers, families with caring responsibilities or other pressures, it meant they had little time or enthusiasm for engaging with DHIs [41, 46-48, 50, 53, 54]. People were also worried about the privacy and security of personal health information as it could be compromised online and potentially disclosed to a partner, family, friend, co-worker, or employer or used by private industry or governments to infringe on their rights [42-44, 50, 52, 55, 56]. Digital literacy was another commonly cited barrier that hindered engagement as those who had little or no experience of using computer or mobile devices and lacked the necessary technical skills struggled to take part. In a few cases individuals had problems with English literacy as it was not their first language [44-49, 52, 55]. A lack of computer or mobile equipment and access to the Internet was another reason some people could not register for a DHI [44, 46-50]. For some this was due to the prohibitive costs involved and people's inability to access affordable technologies [44, 50-52].

"I'm very wary of the internet, we leave digital footprints wherever we go and you never know what's going to come back and haunt you and I think the more that you are in a professional working environment the more you need to be careful about what you put online. You've got to keep it within certain parameters." - Barrier (CA-ri) [44]

\section{Engagement and recruitment approach}

The type of strategy or approach used to sign patients and the public up to DHIs was the third major theme that affected enrolment. Personal recommendations from trusted people such as family members, friends or peers was important and the support these social groups provided offline helped people to engage with and register for a technology, whereas those who lacked support often failed to sign up $[41,48,50,53,54]$. Active promotion and recruitment strategies, that were personalised where possible, were also beneficial as they helped reach the right audience and convince them to take part $[41,42,46]$. In one study a health professional acted as a gatekeeper and mediated engagement and enrolment to ensure the right type of patients were registered for a telehealth service [49]. Altruistic reasons for engagement were also mentioned in one paper as some participants working at a university signed up for a DHI to support colleagues conducting research [41].

"I make that decision by the patient's need. If their diabetes is poorly controlled, then you need to use more tools to get them under control... you don't really need it with all your patients with diabetes. You need it on the ones that need extra help." Facilitator (CP-e) [49]

On the other hand, some people lacked an awareness of the existence of technology that could be used to support their health as it was not widely promoted. Public health education was not a fundamental aspect of some strategies used so people had a poor understanding of what a DHI could do, which meant they had little interest in signing up to use it $[46,47,59]$. A further problem was that some people had difficulties understanding the recruitment message, who it came from, why it was relevant to them or how to go about enrolling in a digital platform [41, 51]. A lack of clinical endorsement was a clear barrier for others who felt that if their healthcare provider would not promote digital health or use it themselves, then it was probably of limited value $[46,57]$. On the other hand, if health professionals or trusted organisations affiliated with healthcare were supportive this reassured people it was worth signing up to $[44,52]$.

"I would probably if I knew that the physician would access that prior to an appointment. If the physician didn't read it, if it was more of a personal thing ljust for me to do], I don't know if I would kind of follow through with that." - Barrier (CP-i) [57]

\section{Quality of the Digital Health Intervention (DHI)}

The final theme affecting patients and the public's ability to engage and enrol in digital health relates to the perceived quality of the information or interaction provided via technology. Some people signed up for a digital product or service as they felt it provided a more open communications channel with their healthcare provider $[45,57]$, while others gained the social support they needed online quickly and easily which enabled them to better manage their illness $[52-54,57]$. In one paper, individuals cited medical errors they had personally experienced due to a lack of technology and welcomed electronic systems as a way to minimise mistakes and improve the quality of health data and care they received [47]. In addition, technology that was as automated as possible and integrated with other systems was seen to be more usable which would encourage enrolment [56]. 
"I was so down and my peers/family couldn't handle it and I needed someone who could tell me that it would be OK and that it was normal but also that I needed to stop feeling sorry for myself in a nice way... I just went online and look for my support group [sic]." Facilitator (RM-s) [53]

However, others felt they would receive a poorer level of care due to the impersonal nature of electronic media as it lacked the nuances of human interaction, in particular where therapeutic relationships with clinicians were important social outlets or sensitive health issues were involved [45-48, 50, 54-57, 59].

"I don't think you would get the same feeling as if you were one-to-one in a room. You get more, you get to know the other person, so in a way you would. To me it would be like talking to a machine." -

Barrier (RM-ia) [45]

In some cases the quality of health information accessed online was thought to be unreliable, without input from a qualified doctor or nurse, and the potential for identity fraud made it difficult for some people to trust advice from virtual health professionals [45, 55-57]. In one paper, abusive or threatening behaviour that could develop in virtual relationships was a barrier that prevented others from engaging and enrolling [50]. Finally, the usability of the DHI also featured under quality as some individuals felt they would not sign up if it was too slow and cumbersome to register or use it $[41,47,48,56]$.

\section{Developing a conceptual understanding of digital health engagement and recruitment processes}

We have used our catalogue of barriers and facilitators, conceptualised through the lens of NPT to develop an initial conceptual model of engagement and recruitment processes to help illuminate the myriad factors that affect patients' and the publics' ability to take part in digital health (see Fig. 2). This DIgital Health EnGagement MOdel (DIEGO) centres on four main processes that people need to work through when first deciding if they wish to engage with a DHI (decision-making) and then when signing up to it (operationalising). In making a decision about whether to engage, people need to make sense of a DHI and consider its quality. From there, people must operationalise their decision by gaining adequate support to enrol and actively register for the DHI. Each of these four key processes are made up of a number of subcomponents that affect how patients and the public progress through the digital health engagement and enrolment journey. This preliminary conceptual model services as a useful heuristic to help people think through key engagement and enrolment issues that merit attention. Further investigation will be necessary to determine the relative importance of different elements of the model.

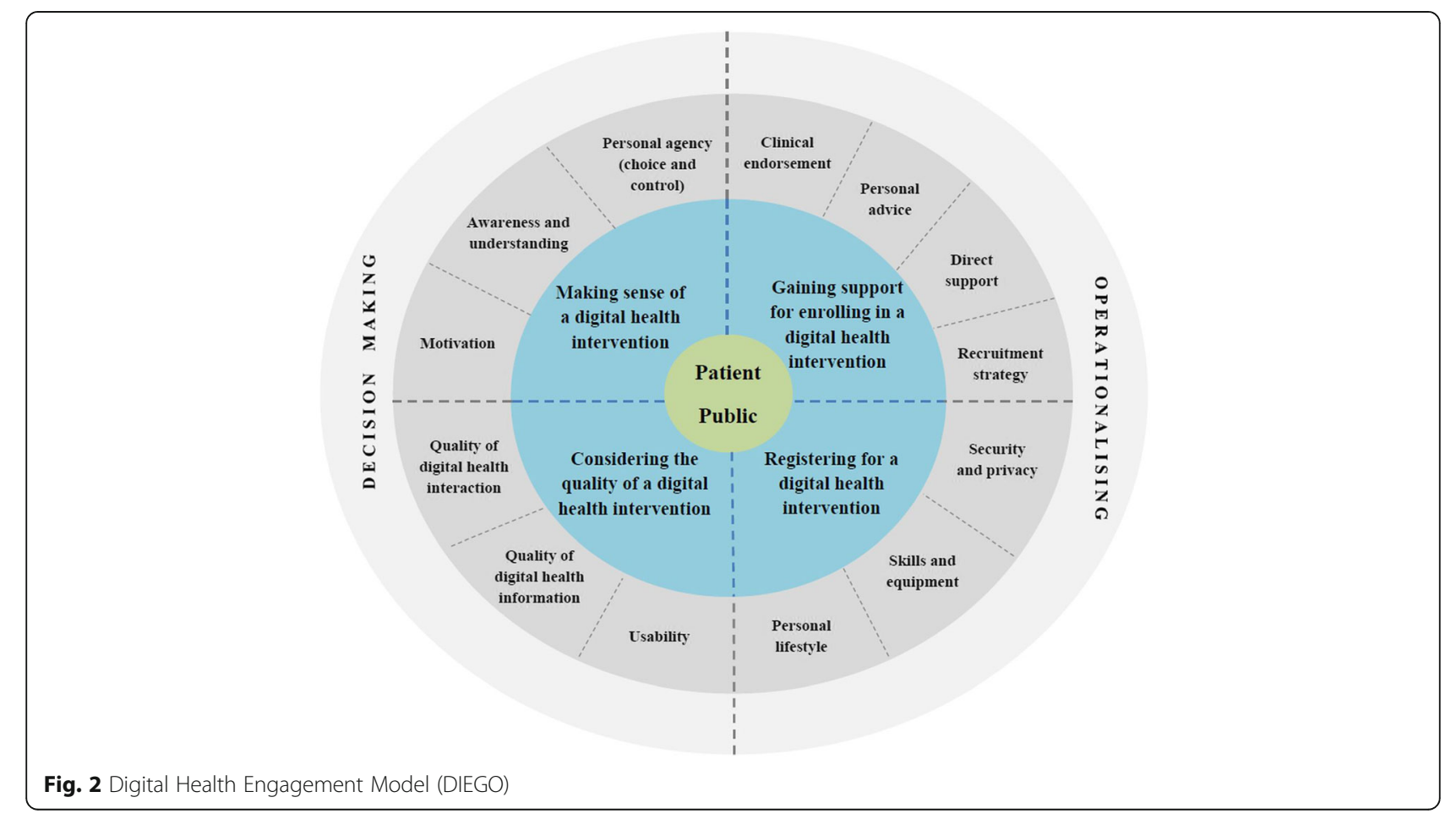




\section{Discussion}

This review provides a summary of reported engagement and recruitment strategies, a catalogue of barriers and facilitators patients and the public experience when engaging and enrolling in DHIs as well as a preliminary conceptual model of key elements in this process. While none of the included papers comprehensively covered the entire process of engaging with and signing up to a DHI each study examined one or more aspects of people's positive and negative experiences.

\section{Existing knowledge and future research}

This systematic review explores how patients and the public engage with and enrol in a broad range of DHIs. Its findings support and expand those of an earlier review, which primarily looked at people accessing health information online [21]. One theme from that paper which affected engagement was the "characteristics of users", such as their age, ethnicity, economic status and educational attainment; this did not emerge strongly from our review given the diversity of participants involved. However, the educational level people attain was one factor in our review that did affect engagement with digital health, as those with poor computer skills found it challenging to enrol which is in keeping with previous literature. In addition, as very few of the included studies in our review involved people over sixty years of age and other literature on usability points to older adults having more difficulties with digital health [60, 61], it would be wise to explore in more depth why this population do or do not engage with and enrol in DHIs. Similarly, ethnicity and socioeconomic status were not well described in the papers in this review so definitive conclusions about how culture and social position affects engagement with DHIs cannot be made. Literacy skills [62-64] and being able to pay for the technology [65] do impact on people's ability to interact with and use DHIs, which is consistent with the findings of our review.

This review incorporated several different DHIs but newer platforms such as wearable devices are also emerging in this space [66] and more will undoubtedly follow as nanotechnology and biotechnology take off. It will therefore be important to update this review in due course to incorporate these new trends, expand on the taxonomy of engagement and enrolment strategies used to encourage people to sign up to them and the barriers and facilitators experienced in the process. However, it is likely that many of the same issues will emerge as the generative mechanisms of digital health engagement and enrolment have been teased out through our conceptual work when developing the new DIgital Health EnGagement MOdel (DIEGO).

\section{Limitations}

This review followed the ENTREQ guidelines for the reporting of systematic reviews of qualitative studies but it does have some limitations. The search strategy used introduced a number of constraints. Publications included were in the English language only; while this may have excluded potentially useful studies, there is evidence that limiting studies in this way does not introduce significant bias [67]. The search dates were limited to studies after the year 2000 but as this is a rapidly evolving sphere we believe this is justifiable. The selection criteria specifically excluded studies discussing recruitment to RCTs, as the focus here was on engagement and enrolment to "real-world" DHIs. Furthermore, many DHIs are developed in the commercial space and marketed to consumers but these have not been formally evaluated through rigorous research and so the literature is limited to only those applications that have undergone academic evaluation [68]. This does mean that some pertinent evidence could have been missed. The analysis and synthesis of the qualitative studies was based on our review of published data and not the original data, which may result in the loss of some important explanatory context. In addition, cultural differences in how people perceive and engage with DHIs, is not well understood, and the existing literature presents a predominantly Western viewpoint, which is a limitation. Furthermore, issues of socioeconomic disadvantage are not systematically addressed in the literature, which is another limitation. However, although more research will be required, based on the literature published to date, a number of recommendations are made about how to address the difficulties patients and the public face when engaging or enrolling in DHIs and what health professionals, health service managers, policy makers, industry and others need to consider to overcome these challenges.

\section{Recommendation 1}

This review has emphasised that people struggle to "make sense" of digital health and that it is not yet considered the "norm". BOTT suggests that use of health services, which includes digital healthcare are social experiences that are "governed by expectations of accountability and norms of membership and behaviour" [38]. This leads us to suggest that:

\section{There is a need to invest in raising the profile of digital health products and services so patients and the public are knowledgeable about them.}

Work is needed to increase public awareness of different technologies and understanding of how they work, what benefits they can bring and potential risks 
inherent in using them. Further research is needed on novel ways to engage and educate the public about digital health as well as more investment in traditional forms of public health education [69]. Identifying which engagement and recruitment strategies are most effective for different groups of patients, consumers and technologies would also be beneficial $[14,70]$, as detailed descriptions of these were largely missing from the included studies. While communicating via mass media such as newspapers, television and radio advertising is becoming less popular as these services move online, the virtual space offers numerous opportunities to provide interactive educational content and promote collaborative sharing and learning, especially through social media [71]. However, this is dependent on patients and the public having access to digital platforms in the first instance, which as outlined in the review is not always feasible for some so more digital inclusion initiatives are necessary to address the digital divide [64]. Identifying and measuring which engagement and enrolment strategies are most effective for different groups of patients, consumers and technologies would also be beneficial to improve awareness and understanding of DHIs [14, 70], as detailed descriptions of these were largely missing from the included studies. A range of metrics could be developed, such as the cost of engaging an individual through a particular strategy or the time taken to recruit a critical mass of users via a certain method, to help determine which approaches are most successful and some such as web analytics are already in use [72]. It will be important that future studies describe engagement or recruitment strategies in greater detail to improve the fidelity and impact of these approaches [73]. Development of a template for engagement and enrolment strategies analogous to the one developed for intervention description and replication called the Template for Intervention Description and Replication (TIDieR) [74] would be helpful.

\section{Recommendation 2}

This review has shown that individuals consider several different quality aspects of a digital health product or service before signing up to it. The perceived value of the electronic health service interaction or the information people can convey and receive through digital means is a critical elements that must be better in one or more ways than the current standards of care to encourage people to register for it. BOTT reminds us that "relational networks can act as collective agents to negotiate and navigate healthcare services" [38]. Thus, we would suggest that:

Technology that incorporates and enhances communication, social interaction and relationships with formal and informal care providers and peers with similar health issues, both online and offline, may help ensure engagement and enrolment, as people can quickly and easily access the social support they need to manage their wellbeing.

Gamification [75], social networking applications [76] and wearable technologies [66] are currently being explored to improve the usability and social connectedness of digital health products and services and further work should explore how these can contribute to engagement and enrolment. There is growing evidence that additional support, such as peer support, can be an effective strategy for reaching individuals that healthcare has traditionally described as "hard to reach" [77, 78]. More research examining whether or how these new platforms can help address the different barriers to engagement and recruitment would be useful.

\section{Recommendations 3 and 4}

This review has emphasised that gaining the right support to enrol is another important element in digital health engagement and recruitment processes. This support can take numerous forms but it is clear that clinical endorsement from trusted health professionals or organisations is helpful in getting people to engage and sign up to digital health. For consumer facing technology personal recommendations and direct help from family and friends can be useful. Drawing on BOTT's relational networks [38] to direct engagement with digital health we suggest that:

Accreditation and endorsement by respected clinical organisations or clinicians will be an important factor promoting engagement with digital health.

\section{And}

\section{Marketing and engagement activities should consider targeting not just the individuals with a given condition or health issue but their wider relational and support networks, whose input may be a crucial factor in deciding uptake of new digital health initiatives.}

More research on whether DHIs should be accredited and approved by healthcare organisations and clinicians and how this should be done, given legal and ethical implications, would also be useful to provide guidance to individual healthcare professionals as well as local and national health services on how to promote engagement in digital health [68]. Health professionals have been known to act as gatekeepers to DHIs and block patient recruitment [11]. More research on how to address this issue would be beneficial as it is an important avenue by 
which patients and the public can learn about DHIs and enrol in them.

\section{Recommendation 5}

The published literature to date is clear that even if a DHI is high quality, well publicised and promoted, and patients and consumers are aware of and supported to sign up to it, there is no guarantee that they will register for it as other factors can affect their ability to enrol. In particular, busy lifestyles, with competing demands on individuals for their time and commitment, often taken precedence over personal health. As BOTT highlights people's "functional performance" is mediated by their cognitive and material capacity and "exercise of agency is constrained by controls on service content and the distribution of opportunities of care, and by the social and economic resources available" [38]. This leads us to suggest that:

\section{Digital health engagement and enrolment strategies along with the products and services should be better designed and tailored where possible to lessen rather than increase the self-care burden of treatment people endure. This could enable them to integrate digital health with their current lifestyle, as a one-size fits all approach is unlikely to be effective.}

As disease trends change over time DHIs must be designed in a flexible manner to accommodate the changing demographic and health landscape. For example, as multimorbidity becomes more commonplace it will impact on the future design requirements of many DHIs, which typically have a single disease focus and are not yet capable of providing holistic self-management solutions for patients and the public [79]. In the future, DHIs may also need to combine the health and social care needs of individuals, as these are often closely intertwined, and some health systems are now moving towards integrating health and social care services [80, 81]. Research in this space is exploring personalising technology through co-design and other participatory methods to improve usability as patients and the public are often excluded from this process and their input will be vital if DHIs are to be successful [82, 83]. Furthermore, digital health readiness assessments are under development to see if an individual has the capacity for a DHI, what form this should take, and what engagement and enrolment strategies suit them [84]. More work in this area would be beneficial and DIEGO could be a starting point for the development of future digital health readiness toolkits that focus on the patient and consumer perspective.

The review has reinforced the fact that usability is a significant factor in a person's decision to sign up to a DHI. Therefore, digital platforms should have simple and short enrolment processes and it is essential that the systems themselves are easy to use so they are not burdensome, as this is a key factor that will affect uptake. In addition, people expect more integrated and automated systems that are continuously available. Interoperability issues between technologies and electronic systems are currently being tackled [85] and the development of application programming interfaces [86] are helping to close this gap further but more work on how to provide seamless digital health services would be helpful to encourage patients and the public to sign up to them.

\section{Recommendation 6 and 7}

This review has also highlighted that poor digital literacy skills, the cost of some technologies and the fact that high speed Internet access is still not ubiquitous prevents many people from signing up for a digital health intervention. In keeping with the exercise of agency expressed in BOTT [38] we suggest that:

\section{More investment in digital upskilling mechanisms and technical infrastructure is needed alongside engagement and recruitment strategies if digital health uptake is to be enhanced.}

\section{And}

Better funding models need to be put in place to help ensure equity of access to digital health products and services.

Research in this space is emerging [63-65] but further work is necessary to illuminate the best means of achieving this for different groups of patients and the public. There is an assumption that these issues will become less of a factor over time, as the younger generation who are more digitally literate get older, and $4 \mathrm{G}$ and $5 \mathrm{G}$ telecommunication networks are rolled out. However, there is evidence that the penetration of technology in society does not guarantee that adolescents have more chance to learn and use IT, as numerous factors such as home IT access, gender and socio-economic status can affect children's digital skills [87] and recent statistics show older adults still continue to struggle to use digital health [88]. While many countries are investing in upgrading their network capacity, the ability to pay for technology whether it is the hardware, software, network connectivity or data consumption necessary to utilise DHIs will not always be feasible for some people [89], especially those in low and middle-income nations. Therefore, to prevent further inequalities in health developing more work on these issues is necessary.

\section{Recommendation 8}

Finally, this review underscores that security and privacy of personal information and the anonymity of digital 
health platforms affect engagement. Whether patients and the public consider their data to be safe, secure and used appropriately by those who control and manage it is a consideration they make before enrolling. BOTT underscores the importance of "social capital", which is access to information and material resources, to enhance people's "structural resilience" or the ability to adapt to adversity and treatment burden [38]. Thus, we suggest that:

\section{The public should be made more aware of the potential security risks with digital health products and services and better regulations need to be put in place to protect them to encourage engagement.}

Given that some technology sectors such as the mobile app industry are completely unregulated [90-92] and cybercrime is prevalent [93], it would also be pertinent to inform the public about the potential risks involved in using digital health products and services and what is being done to protect the privacy and security of their data.

\section{Conclusion}

It is clear from our framework of barriers and facilitators that digital health engagement and recruitment processes are complex, with many interconnecting factors that affect patients' and the public's ability to engage and enrol in a technology and there remains outstanding gaps in knowledge. Our preliminary Digital Health Engagement Model (DIEGO) provides a useful checklist for health professionals, health service managers, policy makers, academia, industry and others to consider when implementing digital health in the real world and will be particularly helpful for newcomers to the field. Future research must aim to describe engagement or enrolment strategies in greater detail, including theoretical underpinnings if we are to more effectively study, classify, and learn which approaches are more likely to succeed.

\section{Additional files}

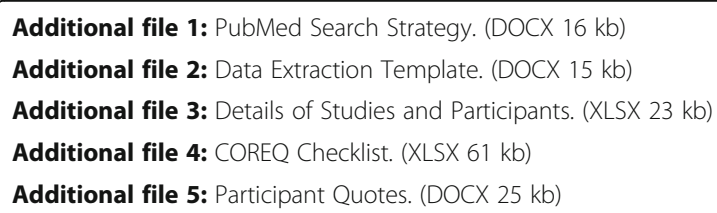

\section{Abbreviations}

BOTT: Burden of treatment theory; COREQ: Consolidated criteria for reporting qualitative research; DIEGO: Digital health engagement model; ENTREQ: Enhancing transparency in reporting the synthesis of qualitative research; IVR: Interactive voice recognition; NPT: Normalization process theory; PCs: Personal computers; PHRs: Personal health records; RCT: Randomized controlled trials; SMS: Short message service; TIDieR: Template for intervention description and replication

\section{Acknowledgements}

We would to thank Stephen Brewster from Text Mining Solutions Ltd who assisted the research team with the implementation of the search strategy for this systematic review.

\section{Funding}

We would like to acknowledge Innovate UK (formerly known as the UK Technology Strategy Board) who part funded this work through a research grant. The funder had no part in the design of this review and the views expressed in this paper are those of the authors and not necessarily those of Innovate UK.

\section{Availability of data and materials}

The data that supports the findings of this systematic review can be found in main paper and the additional supporting files.

\section{Authors' contributions}

SOC, FM and COD conceptualised the study and designed the review. JG and SG designed the search strategies with input from SOC and FM. SOC and $\mathrm{PH}$ conducted the screening, quality assessment, data extraction and analysis with support from FM and COD where necessary. SOC wrote the first draft of the review paper. All authors contributed to the writing of the manuscript and approved the final version of the manuscript.

\section{Competing interests}

The authors declare that they have no competing interests

\section{Consent for publication}

Not applicable.

Ethics approval and consent to participate

Not applicable.

\section{Author details}

${ }^{1}$ General Practice and Primary Care, Institute of Health and Wellbeing, University of Glasgow, 1 Horslethill Rd, Glasgow G12 9LX, UK. ${ }^{2}$ School of Nursing, Midwifery and Social Work, University of Manchester, Manchester, UK. ${ }^{3}$ York Health Economics Consortium Ltd, York, UK.

Received: 20 August 2016 Accepted: 3 September 2016 Published online: 15 September 2016

\section{References}

1. Georgsson M, Staggers N. Quantifying usability: an evaluation of a diabetes mHealth system on effectiveness, efficiency, and satisfaction metrics with associated user characteristics. J Am Med Inform. 2016;23:5-11.

2. Reti SR, Feldman HJ, Ross SE, Safran C. Improving personal health records for patient-centered care. J Am Med Inform Assoc. 2010;17:192-5.

3. Mair FS, Haycox A, Williams T. A review of telemedicine cost-effectiveness studies. J Telemed Telecare. 2000;6:38-40.

4. May C, Mort M, Williams T, Mair F, Gask L. Health technology assessment in its local contexts: studies of telehealthcare. Soc Sci Med. 2003;57:697-710.

5. Pagliari $C$, Detmer $D$, Singleton $P$. Potential of electronic personal health records. BMJ. 2007;335:330-3

6. Devlin AM, McGee-Lennon M, O'Donnell CA, Bouamrane M, Agbakoba R, O'Connor S, et al. Delivering Digital Health and Well-Being at Scale: Lessons Learned during the Implementation of the dallas Program in the United Kingdom. J Am Med Inform Assoc. 2016;23:48-59.

7. Bailey SC, Belter LT, Pandit AU, Carpenter DM, Carlos E, Wolf MS. The availability, functionality, and quality of mobile applications supporting medication self-management. J Am Med Inform Assoc. 2014;21:542-6.

8. Moorhead SA, Hazlett DE, Harrison L, Carroll JK, Irwin A, Hoving C. A new dimension of health care: systematic review of the uses, benefits, and limitations of social media for health communication. J Med Internet Res. 2013;15, e85.

9. Gorst SL, Armitage CJ, Brownsell S, Hawley MS. Home telehealth uptake and continued use among heart failure and chronic obstructive pulmonary disease patients: A systematic review. Ann Behav Med. 2014;48:323-36.

10. Sanders C, Rogers A, Bowen R, Bower P, Hirani S, Cartwright M, et al. Exploring barriers to participation and adoption of telehealth and telecare within the Whole System Demonstrator trial: a qualitative study. BMC Health Serv Res. 2012;12:220. 
11. Miyamoto S, Henderson S, Young H, Ward D, Santillan V. Recruiting Rural Participants for a Telehealth Intervention on Diabetes Self-Management. J Rural Health. 2013;29:69-77.

12. Lakerveld J, IJzelenberg W, Van Tulder MW, Hellemans IM, Rauwerda JA, Van Rossum AC, et al. Motives for (not) participating in a lifestyle intervention trial. BMC Med Res Methodol. 2008:8:17.

13. Goel MS, Brown TL, Williams A, Cooper AJ, Hasnain-Wynia R, Baker DW. Patient reported barriers to enrolling in a patient portal. J Am Med Infor Assoc. 2011;18:18-12.

14. O'Connor S, Mair FS, McGee-Lennon M, Bouamrane M, O'Donnell K. Engaging in large-scale digital health technologies and services. What factors hinder recruitment? Stud Health Technol Inform. 2015;210:306-10.

15. Grimshaw JM, Eccles MP, Lavis JN, Hill SJ, Squires JE. Knowledge translation of research findings. Implement Sci. 2012;7:50.

16. Woolf $\mathrm{SH}$. The meaning of translational research and why it matters. JAMA. 2008;299:211-3

17. Varsi C, Gammon D, Wibe T, Ruland CM. Patients' reported reasons for nonuse of an internet-based patient-provider communication service: qualitative interview study. J Med Internet Res. 2013;15, e246.

18. Jimbo M, Shultz CG, Nease DE, Fetters MD, Power D, Ruffin MT. Perceived barriers and facilitators of using a Web-based interactive decision aid for colorectal cancer screening in community practice settings: findings from focus groups with primary care clinicians and medical office staff. J Med Internet Res. 2012;15:e286.

19. Mays N, Pope C, Popay J. Systematically reviewing qualitative and quantitative evidence to inform management and policy-making in the health field. J Health Serv Res Policy. 2005;10:6-20.

20. Hannes K, Booth A, Harris J, Noyes J. Celebrating methodological challenges and changes: reflecting on the emergence and importance of the role of qualitative evidence in Cochrane reviews. Systematic Reviews. 2013;2:84

21. Hardiker NR, Grant MJ. Factors that influence public engagement with eHealth: A literature review. Int J Med Inform. 2011;80:1-12

22. O'Connor S, Hanlon P, Garcia S, Glanville J, O'Donell CA, Mair FS. Barriers and facilitators to engagement and recruitment to digital health interventions: protocol of a systematic review of qualitative studies. BMJ Open. 2016;6e010895.

23. Tong A, Sainsbury P, Craig J. Consolidated criteria for reporting qualitative research (COREQ): a 32-item checklist for interviews and focus groups. Int J Qual Health Care. 2007;19:349-57.

24. Booth A, Hannes K, Harden A, Noyes J, Harris J, Tong A. COREQ (Consolidated Criteria for Reporting Qualitative Studies). In: Moher D, Altman DG, Schulz KF, Simera I, Wager E, editors. Guidelines for Reporting Health Research: A User's Manual. Oxford: Wiley; 2014. p. 214-26.

25. Sandelowski M, Docherty S, Emden C. Focus on qualitative methods Qualitative metasynthesis: issues and techniques. Res Nurs Health. 1997;20: 365-72.

26. Barbour RS. Checklists for improving rigour in qualitative research: a case of the tail wagging the dog? BMJ. 2001;322:1115-7.

27. Atkins S, Lewin S, Smith H, Engel M, Fretheim A, Volmink J. Conducting a meta-ethnography of qualitative literature: lessons learnt. BMC Med Res Methodol. 2008:8:21.

28. Popay J, Rogers A, Williams G. Rationale and Standards for the Systematic Review of Qualitative Literature in Health Services Research. Qual Health Res. 1998;8:341-51.

29. Dixon-Woods M, Sutton A, Shaw R, Miller T, Smith J, Young B, et al. Appraising qualitative research for inclusion in systematic reviews: a quantitative and qualitative comparison of three methods. J Health Serv Res Policy. 2007:12:42-7.

30. Ritchie J, Spencer L. Qualitative data analysis for applied policy research. In: Bryman A, Burgess R, editors. Analysing qualitative data. London: Routledge; 1994. p. 173-94.

31. Oliver SR, Rees RW, Clarke-Jones L, Milne R, Oakley AR, Gabbay J, et al. A multidimensional conceptual framework for analysing public involvement in health services research. Health Expect. 2008;11:72-84.

32. Brunton $\mathrm{G}$, Oliver S, Oliver K, Lorenc T. A Synthesis of Research Addressing Children's, Young People's and Parents' Views of Walking and Cycling for Transport. London: EPPI-Centre, Social Science Research Unit, Institute of Education, University of London; 2006. https://eppi.joe.ac.uk/cms/LinkClick. aspx?fileticket=Yyj-9TBnKKA\%3D\&tabid=1591\&mid=3318. Accessed 15 Feb 2016

33. May C, Finch T. Implementing, embedding, and integrating practices: an outline of normalization process theory. Sociology. 2009:43:535-54.
34. May CR, Mair F, Finch T, MacFarlane A, Dowrick C, Treweek S, et al. Development of a theory of implementation and integration: Normalization Process Theory. Implement Sci. 2009;4:29.

35. Mair FS, May C, O'Donnell CA, Finch T, Sullivan F, Murray E. Factors that promote or inhibit the implementation of e-health systems: an explanatory systematic review. Bulletin of the World Health Organisation. 2012;90:357-64.

36. Gallacher K, Morrison D, Jani B, Macdonald S, May CR, Montori VM, et al. Uncovering Treatment Burden As A Key Concept For Stroke Care: A Systematic Review of Qualitative Research. PLoS Med. 2013;10, e1001473.

37. Mays N, Pope C. Qualitative research: rigour and qualitative research. BMJ. 1995:311:109-12.

38. May CR, Eton DT, Boehmer K, Gallacher K, Hunt K, MacDonald S, et al. Rethinking the patient: using Burden of Treatment Theory to understand the changing dynamics of illness. BMC Health Serv Res. 2014;14:1.

39. Gallacher K, May CR, Montori VM, Mair FS. Understanding patients' experiences of treatment burden in chronic heart failure using normalization process theory. The Annals of Family Medicine. 2011:9:235-43.

40. Tong A, Flemming K, Mclnnes E, Oliver S, Craig J. Enhancing transparency in reporting the synthesis of qualitative research: ENTREQ. BMC Med Res Methodol. 2012;12:181

41. Bardus M, Blake H, Lloyd S, Suggs LS. Reasons for participating and not participating in a e-health workplace physical activity intervention: A qualitative analysis. Int J Workplace Health Man. 2014;7:229-46.

42. Lorimer K, McDaid L. Young men's views toward the barriers and facilitators of Internet-based Chlamydia trachomatis screening: qualitative study. J Med Internet Res. 2013;15, e265.

43. Lorimer K, Martin S, McDaid LM. The views of general practitioners and practice nurses towards the barriers and facilitators of proactive, internetbased chlamydia screening for reaching young heterosexual men. BMC Fam Pract. 2014;15:127.

44. Middlemass J, Davy Z, Cavanagh K, Linehan C, Morgan K, Lawson S, et al. Integrating online communities and social networks with computerised treatment for insomnia: a qualitative study. Br J Gen Pract. 2012;62:e840-50.

45. Beattie A, Shaw A, Kaur S, Kessler D. Primary-care patients' expectations and experiences of online cognitive behavioural therapy for depression: a qualitative study. Health Expect. 2009;12:45-59.

46. Flynn D, Gregory P, Makki H. Expectations and experiences of eHealth in primary care: a qualitative practice-based investigation. Int J Med Inform. 2009;78:588-604.

47. Greenhalgh T, Wood GW, Bratan T, Stramer K, Hinder S. Patients' attitudes to the summary care record and HealthSpace: qualitative study. BMJ. 2008;336: 1290-5.

48. Greenhalgh T, Hinder S, Stramer K, Bratan T, Russell J. Adoption, nonadoption, and abandonment of a personal electronic health record: case study of HealthSpace. BMJ. 2010;341:c5814.

49. Hopp FP, Hogan MM, Woodbridge PA, Lowery JC. The use of telehealth for diabetes management: a qualitative study of telehealth provider perceptions. Implement Sci. 2007;2:14.

50. Horvath KJ, Danilenko GP, Williams ML, Simoni J, Amico KR, Oakes JM et al. Technology use and reasons to participate in social networking health websites among people living with HIV in the US. AIDS Behav. 2012;16:900-10

51. Speirs KE, Grutzmacher SK, Munger AL, Messina LA. Recruitment and retention in an SMS-based health education program: Lessons learned from Text2BHealthy. Health Inform J. 2015:1460458215577995.

52. Fukuoka Y, Kamitani E, Bonnet K, Lindgren T. Real-time social support through a mobile virtual community to improve healthy behavior in overweight and sedentary adults: a focus group analysis. J Med Internet Res. 2011;13, e49.

53. Im EO, Im Lee B, Chee W. "Shielded from the Real World": Perspectives on Internet Cancer Support Groups by Asian Americans. Cancer Nurs. 2010;33, e10.

54. Dasgupta K, Da Costa D, Pillay S, De Civita M, Gougeon R, Leong A, et al. Strategies to optimize participation in diabetes prevention programs following gestational diabetes: a focus group study. PLoS One. 2013;8, e67878.

55. Hottes TS, Farrell J, Bondyra M, Haag D, Shoveller J, Gilbert M. Internetbased HIV and sexually transmitted infection testing in British Columbia, Canada: opinions and expectations of prospective clients. J Med Internet Res. 2012:14, e41. 
56. Shoveller J, Knight R, Davis W, Gilbert M, Ogilvie G. Online sexual health services: examining youth's perspectives. Can J Public Health. 2012;103:14-8.

57. Winkelman WJ, Leonard KJ, Rossos PG. Patient-perceived usefulness of online electronic medical records: employing grounded theory in the development of information and communication technologies for use by patients living with chronic illness. J Am Med Inform Assoc. 2005;12:306-14.

58. Das A, Faxvaag A. What influences patient participation in an online forum for weight loss surgery? A qualitative case study. Interact J Med Res. 2014;3, e4.

59. Trujillo Gómez JMT, Díaz-Gete L, Martín-Cantera C, Escurriola MF, Moreno $M L$, Leandro RB, et al. Intervention for Smokers through New Communication Technologies: What Perceptions Do Patients and Healthcare Professionals Have? A Qualitative Study. PLoS One. 2015;10, e0137415.

60. Choi NG, DiNitto DM. The digital divide among low-income homebound older adults: Internet use patterns, eHealth literacy, and attitudes toward computer/Internet use. J Med Internet Res. 2013;15, e93.

61. Selwyn N, Gorard S, Furlong J, Madden L. Older adults' use of information and communications technology in everyday life. Ageing Soc. 2003;23:561-82.

62. Cashen MS, Dykes P, Gerber B. eHealth technology and Internet resources: barriers for vulnerable populations. J Cardiovas Nurs. 2004;19:209-14.

63. Kontos E, Blake KD, Chou WYS, Prestin A. Predictors of eHealth usage: insights on the digital divide from the Health Information National Trends Survey 2012. J Med Internet Res. 2014;16, e172.

64. Tinder Foundation. Doing Digital Inclusion: Unpaid Carers Handbook. http:// www.tinderfoundation.org/our-thinking/research-publications/doing-digitalinclusion-carers-handbook. Accessed 8 Sept 2016.

65. Neter E, Brainin E. eHealth literacy: extending the digital divide to the realm of health information. J Med Internet Res. 2012;14, e19.

66. Patel MS, Asch DA, Volpp KG. Wearable devices as facilitators, not drivers, of health behavior change. JAMA. 2015;313:459-60.

67. Moher D, Pham B, Lawson ML, Klassen TP. The inclusion of reports of randomised trials published in languages other than English in systematic reviews. Health Technol Assess. 2003;7:1-90.

68. Huckvale K, Prieto JT, Tilney M, Benghozi PJ, Car J. Unaddressed privacy risks in accredited health and wellness apps: a cross-sectional systematic assessment. BMC Med. 2015;13:1.

69. Norman CD, Skinner HA. eHealth literacy: essential skills for consumer health in a networked world. J Med Internet Res. 2006;8, e9.

70. Thompson D, Canada A, Bhatt R, Davis J, Plesko L, Baranowski T, et al. eHealth recruitment challenges. Eval Program Plan. 2006;29:433-40.

71. Kaplan AM, Haenlein M. Users of the world, unite! The challenges and opportunities of Social Media. Bus Horiz. 2010;53:59-68.

72. Crutzen R, Roosjen JL, Poelman J. Using Google Analytics as a process evaluation method for Internet-delivered interventions: an example on sexual health. Health Promot Int. 2013;28:36-42.

73. Carroll C, Patterson M, Wood S, Booth A, Rick J, Balain S. A conceptual framework for implementation fidelity. Implement Sci. 2007;2:1.

74. Hoffmann TC, Glasziou PP, Boutron I, Milne R, Perera R, Moher D, et al. Better reporting of interventions: template for intervention description and replication (TIDieR) checklist and guide. BMJ. 2014;348:g1687.

75. King D, Greaves F, Exeter C, Darzi A. 'Gamification': Influencing health behaviours with games. J R Soc Med. 2013;106:76-8.

76. Laranjo L, Arguel A, Neves AL, Gallagher AM, Kaplan R, Mortimer N, et al. The influence of social networking sites on health behavior change: a systematic review and meta-analysis. J Am Med Inform Assoc. 2015;22:243-56.

77. Sokol R, Fisher E. Peer Support for the Hardly Reached: A Systematic Review. Am J Public Health. 2016;106:e1-8.

78. Lauckner HM, Hutchinson SL, Lauckner H. Peer support for people with chronic conditions in rural areas: a scoping review. Rural Remote Health. 2016;16:3601.

79. Zulman DM, Jenchura EC, Cohen DM, Lewis ET, Houston TK, Asch SM. How can eHealth technology address challenges related to multimorbidity? Perspectives from patients with multiple chronic conditions. J Gen Inter Med. 2015;30:1063-70.

80. Stewart A, Petch A, Curtice L. Moving towards integrated working in health and social care in Scotland: from maze to matrix. J Interprof Care. 2003;17: 335-50.

81. Cameron A, Lart R, Bostock L, Coomber C. Factors that promote and hinder joint and integrated working between health and social care services: a review of research literature. Health Soc Care Community. 2014;22:225-33.
82. McHattie LS, Cumming G, French T. Transforming patient experience: health web science meets medicine 2.0. Medicine 20. 2014:3:e2

83. Imison C, Castle-Clarke S, Watson R, Edwards N. Delivering the benefits of digital health care. Nuffield Trust. 2016. http://www.nuffieldtrust.org.uk/sites/files/ nuffield/nutj4099_healthtechreport_16.2.16_web.pdf. Accessed 17 Feb 2016.

84. Jones R. Development of a questionnaire and cross-sectional survey of patient ehealth readiness and ehealth inequalities. Medicine 20. 2013;2:e9.

85. Benson T. Principles of health interoperability HL7 and SNOMED. London: Springer Science \& Business Media; 2012.

86. Sachdeva S, Bhalla S. Semantic interoperability in standardized electronic health record databases. J Data Inform Quality. 2012;3:1.

87. Zhong ZJ. From access to usage: The divide of self-reported digital skills among adolescents. Comp \& Educ. 2011:56:736-46.

88. Levine DM, Lipsitz SR, Linder JA. Trends in Seniors' Use of Digital Health Technology in the United States, 2011-2014. JAMA. 2016;316:538-40.

89. Yamin CK, Emani S, Williams DH, Lipsitz SR, Karson AS, Wald JS, et al. The digital divide in adoption and use of a personal health record. Arch Intern Med. 2011;171:568-74

90. Huckvale K, Adomaviciute S, Prieto JT, Leow MKS, Car J. Smartphone apps for calculating insulin dose: a systematic assessment. BMC Med. 2015;13:1.

91. Wicks P, Chiauzzi E. 'Trust but verify'-five approaches to ensure safe medical apps. BMC Med. 2014;13:1.

92. Boulos MNK, Brewer AC, Karimkhani C, Buller DB, Dellavalle RP. Mobile medical and health apps: state of the art, concerns, regulatory control and certification. Online J Public Health Inform. 2014;5:229.

93. Perakslis ED. Cybersecurity in health care. N Engl J Med. 2014:371:395-7.

94. Treweek S, Mitchell E, Pitkethly M, Cook J, Kjeldstrom M, Taskila T, et al. Strategies to improve recruitment to randomised controlled trials. Cochrane Database Syst Rev. 2010;(Issue 4):Art. No.: MR000013. doi:10.1002/14651858. MR000013.pub5. 